Polymer Journal, Vol. 39, No. 9, pp. 945-952 (2007)

(C) 2007 The Society of Polymer Science, Japan

\title{
N-Phthaloylated Chitosan as an Essential Precursor for Controlled Chemical Modifications of Chitosan: Synthesis and Evaluation
}

\author{
Keisuke KuRITA, ${ }^{1, \dagger}$ Hiroyuki IKedA, ${ }^{1}$ Manabu ShImoJoh, ${ }^{2}$ and Jin YAnG $^{1}$ \\ ${ }^{1}$ Department of Materials and Life Science, Faculty of Science and Technology, Seikei University, \\ 3-3-1 Kichijoji-Kitamachi, Musashino 180-8633, Japan \\ ${ }^{2}$ Research and Development Department, Toyo Suisan Kaisha, Ltd., \\ 2-13-40 Kohnan, Minato-ku, Tokyo 108-8501, Japan
}

(Received May 3, 2007; Accepted June 14, 2007; Published July 31, 2007)

\begin{abstract}
In view of the importance of phthaloylated chitosan as a key intermediate that allows controlled modification reactions of chitosan, phthaloylation of chitosan was studied in detail to elucidate the substitution behavior and to establish a reliable method for preparing structurally well-defined $N$-phthaloyl-chitosan. The reaction of chitosan with phthalic anhydride in $N, N$-dimethylformamide resulted in $N, O$-phthaloylation, and the $O$-phthaloyl groups had to be removed through tritylation-detritylation, hydrolysis, or alcoholysis to afford $N$-phthaloyl-chitosan. In the presence of some water, however, perfect discrimination of the functional groups became possible, and selectively and quantitatively $N$-phthaloylated chitosan could be synthesized in a simple one-step reaction. The resulting $N$-phthaloyl-chitosan exhibited higher reactivity than $\mathrm{N}, \mathrm{O}$-phthaloylated chitosan as confirmed by tritylation and is promising as a precursor for C-6 substitution. [doi:10.1295/polymj.PJ2007032]

KEY WORDS Chitosan / Phthaloylation / Chemical Modification / Protection / Deprotection / Soluble Precursor /
\end{abstract}

Despite the high potentials of the amino polysaccharide chitin and the derived chitosan as biofunctional polymeric materials in various fields such as medicine, toiletries, agriculture, food processing, and biotechnology, ${ }^{1}$ their utilization is still limited because of the poor solubility and processability. These amino polysaccharides are considered to be promising as starting materials for developing new materials with various advanced functions through chemical modifications. ${ }^{2}$ Such studies on developing polysaccharide-based functional materials are, however, delayed primarily due to the difficulty in preparing well-defined derivatives and hence in discussing the structure-property relationship.

Chitin and chitosan are not soluble in ordinary organic solvents and moreover, they have three kinds of reactive groups in their repeating units, which makes the controlled chemical modification reactions difficult. To finely control the modification reactions at a specified functional group, it is necessary to use appropriate protection-deprotection techniques and to conduct the reactions in solution using organosoluble intermediates under mild conditions.

Of some protective groups, phthaloyl is particularly attractive for the amino group of chitosan from all the practical viewpoints of protection, deprotection, and solubilization. ${ }^{3,4}$ Series of regioselective and quantitative modification reactions have become possible with phthaloyl-protected chitosan to introduce sugar branches at C-6, leading to the synthesis of nonnatural branched polysaccharides. ${ }^{5}$ Phthaloylated chitosan also enables various other modification reactions and has proved highly useful and versatile for efficient chemical modifications in controlled manners to give well-defined derivatives. ${ }^{4}$ Phthaloylated chitosan has thus become indispensable as an organosoluble precursor in designing and constructing desirable molecular architectures on chitosan and chitin.

Moreover, some derivatives from phthaloylated chitosan are also outstanding intermediates as reaction precursors for further chemical modifications. For instance, introduction of the triphenylmethyl (trityl) group at C-6 of the phthaloylated chitosan followed by dephthaloylation gives trityl-chitosan, which is soluble in organic solvents and convenient to carry out the reactions of the free amino group in solution. . $^{6}$

Phthaloylation is now regarded as a most common technique for solubilization as well as protection of multifunctional chitosan to prepare various derivatives. However, phthaloylated chitosan thus far used actually has $O$-phthaloyl groups, since treatment of chitosan with phthalic anhydride results in partial $O$ phthaloylation in addition to the $N$-substitution. ${ }^{10,11}$ Furthermore, the reaction is sensitive to various factors including reaction conditions and the state of chitosan, which often fails to give reproducible results. Though N,O-phthaloylated product is suitable for

${ }^{\dagger}$ To whom correspondence should be addressed (Tel: +81-422-37-3745, Fax: +81-422-37-3871, E-mail: kurita@st.seikei.ac.jp). 
some modification reactions, ${ }^{12,13}$ the $O$-phthaloyl group is an obstacle in most cases to quantitative and regioselective substitution. It is thus crucial to establish a procedure to prepare regioselectively $N$ phthaloylated chitosan, and some preliminary results were reported in a previous communication. ${ }^{14}$ Here we report on the detailed studies on the phthaloylation behavior of chitosan and evaluation of the product as a reaction precursor for modification reactions.

\section{EXPERIMENTAL}

\section{General Procedures}

Pulverized shrimp chitin was deacetylated with $40 \%$ aqueous sodium hydroxide at $110^{\circ} \mathrm{C}$ for $5 \mathrm{~h}$ in nitrogen. The deacetylation was repeated two more times, and the product was washed with deionized water and methanol to give fully deacetylated chitosan as a white powder. The degree of deacetylation was confirmed to be 1.0 by conductometric titration. Phthalic anhydride was of reagent grade and used after drying. $\mathrm{N}, \mathrm{N}$-Dimethylformamide (DMF) was dried with calcium hydride and distilled. Pyridine was refluxed with potassium hydroxide and distilled. All the solvents were stored over molecular sieves. IR spectra were taken on a Shimadzu FT/IR-8900 spectrometer. NMR spectra were recorded with a JEOL JNM-LA400D: ${ }^{1} \mathrm{H}$ spectra in deuterated dimethyl sulfoxide (DMSO- $d_{6}$ ) and ${ }^{13} \mathrm{C} \mathrm{CP} / \mathrm{MAS}$ spectra with TOSS (total suppression of spinning sidebands) and TOSDL (TOSS and dipolar dephasing) modes using hexamethylbenzene $(17.36 \mathrm{ppm})$ as the external standard. Elemental analysis was carried out with a Perkin-Elmer 2400 II instrument. Conductometric titration was performed with a TOA conductivity meter CM-20J.

\section{Phthaloylation}

Chitosan $(0.300 \mathrm{~g})$ was treated with phthalic anhydride (3 equivalents to the amino group) in $6 \mathrm{~mL}$ of $\mathrm{DMF}$ or $\mathrm{DMF} /$ cosolvent at $120^{\circ} \mathrm{C}$ for a given time in a nitrogen atmosphere. After the reaction, the mixture was poured into ice water, and the precipitate was collected by filtration. It was washed with methanol thoroughly and dried to give a phthaloylated product as a powdery material. The degree of substitution was determined by the $\mathrm{C} / \mathrm{N}$ value of elemental analysis.

\section{Conductometric Titration of N,O-Phthaloylated Chi- tosan}

Phthaloylated chitosan $(50 \mathrm{mg})$ with a degree of substitution (ds) 1.54 as determined by elemental analysis was dissolved in $4.0 \mathrm{~mL}$ of DMSO, and $5.0 \mathrm{~mL}$ of $0.1 \mathrm{~mol} / \mathrm{L}$ hydrochloric acid was added. Deionized water was added to make the total volume
$60 \mathrm{~mL}$. Conductivity of the solution was measured as $1 / 30 \mathrm{~mol} / \mathrm{L}$ sodium hydroxide was added dropwise. The amount of sodium hydroxide consumed for titrating the free carboxy group was $7.38 \times 10^{-5} \mathrm{~mol}$, which corresponds to the composition of $55 \% \mathrm{~N}, \mathrm{O}$ diphthaloylated unit and $45 \% \mathrm{~N}$-phthaloylated chitosan unit, the ds thus being 1.55.

\section{Preparation of N-Phthaloyl-chitosan by Tritylation of N,O-Phthaloylated Chitosan Followed by Detrityla- tion}

$N, O$-Phthaloylated chitosan (ds $1.54 ; 0.200 \mathrm{~g} ; 0.539$ mol) was added to $5 \mathrm{~mL}$ of pyridine to give a solution, to which was added $1.50 \mathrm{~g}(5.39 \mathrm{~mol})$ of trityl chloride. After stirring in nitrogen at $100^{\circ} \mathrm{C}$ for $24 \mathrm{~h}$, the reaction mixture was cooled to room temperature and poured into $100 \mathrm{~mL}$ of methanol. The precipitated product was collected by filtration, washed thoroughly with methanol, and dried to give $0.252 \mathrm{~g}(88 \%)$ of 2 $\mathrm{N}$-phthaloyl-6-O-trityl-chitosan as a pale tan powdery material. The structure was confirmed by spectral and elemental analysis data. IR $\left(\mathrm{KBr}, \mathrm{cm}^{-1}\right): 3057$ (arom), $1778(\mathrm{C}=\mathrm{O}), 1720(\mathrm{C}=\mathrm{O}), 1150-1000$ (pyranose), 721 (arom), 704 (arom). ${ }^{1} \mathrm{H}$ NMR (DMSO- $d_{6}, \delta, \mathrm{ppm}$ ): 3.0-5.2 (m, pyranose), 6.8-7.2 (m, trityl), 7.5-7.9 (m, $\mathrm{N}$-phthaloyl). Anal. Calcd for $\mathrm{C}_{33} \mathrm{H}_{27} \mathrm{NO}_{6} \cdot 0.7 \mathrm{H}_{2} \mathrm{O}: \mathrm{C}$, 72.57\%; H, 5.24\%; N, 2.56\%; Found: C, $72.58 \%$; H, $5.18 \% ; \mathrm{N}, 2.57 \%$.

2- $N$-Phthaloyl-6- $O$-trityl-chitosan $(0.200 \mathrm{~g})$ obtained above was added to $5 \mathrm{~mL}$ of dichloroacetic acid in small portions, and the resulting solution was stirred at room temperature for $1 \mathrm{~h}$. The solution was added dropwise to $200 \mathrm{~mL}$ of ice water, and the precipitate was collected by filtration. It was washed with methanol overnight and dried to give $98 \mathrm{mg}(88 \%)$ of $\mathrm{N}$-phthaloyl-chitosan as a light tan powdery material. The ds was calculated to be 1.0 from the $\mathrm{C} / \mathrm{N}$ value of the elemental analysis. IR $\left(\mathrm{KBr}, \mathrm{cm}^{-1}\right): 1776$ $(\mathrm{C}=\mathrm{O}), 1712(\mathrm{C}=\mathrm{O}), 1150-1000$ (pyranose), 721 (arom). ${ }^{1} \mathrm{H}$ NMR (DMSO- $\left.d_{6}, \delta, \mathrm{ppm}\right): 3.0-5.2(\mathrm{~m}$, pyranose), 7.5-7.9 (m, $N$-phthaloyl). Anal. Calcd for $\mathrm{C}_{14} \mathrm{H}_{13} \mathrm{NO}_{6} \cdot 0.8 \mathrm{H}_{2} \mathrm{O}: \quad \mathrm{C}, 55.01 \% ; \mathrm{H}, 4.81 \% ; \mathrm{N}$, 4.58\%; Found: C, $55.00 \%$; H, 4.89\%; N, $4.45 \%$.

\section{Preparation of $\mathrm{N}$-Phthaloyl-chitosan by Selective Hydrolysis of $\mathrm{N}, \mathrm{O}$-Phthaloylated Chitosan}

To $2 \mathrm{~mL}$ of $\mathrm{DMF} /$ water $(95 / 5)$ was added $100 \mathrm{mg}$ of $\mathrm{N}, \mathrm{O}$-phthaloylated chitosan (ds 1.54) portionwise, and the solution was heated at $120^{\circ} \mathrm{C}$ with stirring in nitrogen. The solution became a gel in $1.5 \mathrm{~h}$. After $5 \mathrm{~h}$ heating, the mixture was poured into $100 \mathrm{~mL}$ of ice water to isolate the product, which was washed with methanol thoroughly and dried to give $60 \mathrm{mg}$ (76\%) of $\mathrm{N}$-phthaloyl-chitosan. The ds was 1.0 as determined from the $\mathrm{C} / \mathrm{N}$ value of the elemental analysis. The IR 


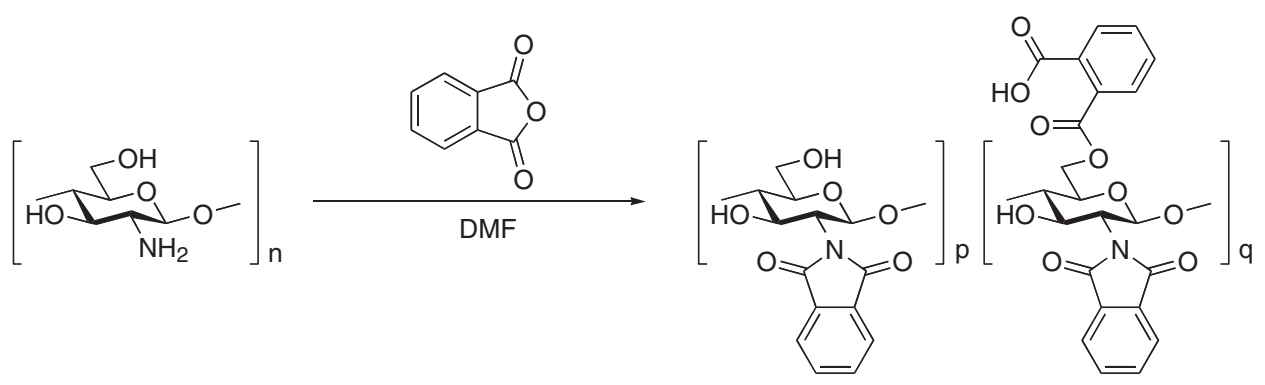

1

Scheme 1.

and ${ }^{1} \mathrm{H}$ NMR spectra were identical with those obtained above. Anal. Calcd for $\mathrm{C}_{14} \mathrm{H}_{13} \mathrm{NO}_{6} \cdot 0.5 \mathrm{H}_{2} \mathrm{O}$ : C, $56.00 \%$; H, 4.70\%; N, 4.66\%; Found: C, 56.11\%; $\mathrm{H}, 4.78 \% ; \mathrm{N}, 4.64 \%$.

\section{Regioselective N-Phthaloylation of Chitosan in DMF/ Water}

Phthalic anhydride $(0.827 \mathrm{~g}, 5.58 \mathrm{mmol})$ was dissolved in $6 \mathrm{~mL}$ of $\mathrm{DMF} /$ water $(95 / 5)$, and $0.300 \mathrm{~g}$ $(1.86 \mathrm{mmol})$ of chitosan was added. The mixture was heated at $120^{\circ} \mathrm{C}$ to give a clear solution in $1 \mathrm{~h}$. The solution then became a gel, which was broken with vigorous stirring. After $8 \mathrm{~h}$, the mixture was cooled to room temperature, and the product was isolated in $500 \mathrm{~mL}$ of ice water. The product was filtered, washed with methanol overnight, and dried to give $0.444 \mathrm{~g}(81 \%)$ of $\mathrm{N}$-phthaloyl-chitosan whose ds was confirmed to be 1.0 from the $\mathrm{C} / \mathrm{N}$ value of the elemental analysis. The IR and ${ }^{1} \mathrm{H}$ NMR spectra were identical with those obtained above. ${ }^{13} \mathrm{C} \mathrm{CP} / \mathrm{MAS}$ NMR (TOSS mode, $\delta, \mathrm{ppm}$ ): 57, 62, 72, 76, 84, and 102 (pyranose), 124, 132, and 134 (arom), 169 $(\mathrm{C}=\mathrm{O}) .{ }^{13} \mathrm{C} \mathrm{CP} / \mathrm{MAS}$ NMR (TOSSDL mode, $\delta$, ppm): 132 (arom), $169(\mathrm{C}=\mathrm{O})$. Anal. Calcd for $\mathrm{C}_{14} \mathrm{H}_{13} \mathrm{NO}_{6} \cdot 0.7 \mathrm{H}_{2} \mathrm{O}: \quad \mathrm{C}, 55.34 \% ; \mathrm{H}, \quad 4.78 \% ; \mathrm{N}$, 4.61\%; Found: C, 55.31\%; H, 4.64\%; N, 4.64\%.

\section{Deprotection of N-Phthaloyl-chitosan}

A mixture of $100 \mathrm{mg}$ of $N$-phthaloyl-chitosan (ds 1.0) in $10 \mathrm{~mL}$ of hydrazine monohydrate was stirred at $80^{\circ} \mathrm{C}$ for $16 \mathrm{~h}$ in nitrogen and poured into $250 \mathrm{~mL}$ of ice water. The product was collected on a glass filter, washed with ethanol in a Soxhlet extractor for $3 \mathrm{~h}$ and with methanol at room temperature for $1 \mathrm{~h}$, and dried. The IR spectrum confirmed the regeneration of chitosan. The recovery yield was $47 \mathrm{mg}$ $(85 \%)$.

\section{Tritylation of N-Phthaloylated Chitosan}

To a solution of $1.91 \mathrm{~g}(6.87 \mathrm{mmol})$ of trityl chloride in $5 \mathrm{~mL}$ of pyridine was added $0.200 \mathrm{~g}(0.687$ mmol) of $N$-phthaloyl-chitosan (ds 1.0), and the mixture was heated at $90^{\circ} \mathrm{C}$ for $24 \mathrm{~h}$. The initially heterogeneous mixture became a solution as the reaction proceeded. After cooling to room temperature, the solution was added to $150 \mathrm{~mL}$ of methanol. The precipitate was filtered, washed with methanol overnight, and dried to give $0.317 \mathrm{~g}(86 \%)$ of $2-\mathrm{N}$-phthaloyl-6$O$-trityl-chitosan as a pale tan powdery material. The ds for the trityl group was determined to be 1.0 from the $\mathrm{C} / \mathrm{N}$ value of the elemental analysis. The IR and ${ }^{1} \mathrm{H}$ NMR spectra were identical with those of the authentic sample prepared above. Anal. Calcd for $\mathrm{C}_{33} \mathrm{H}_{27} \mathrm{NO}_{6} \cdot 0.5 \mathrm{H}_{2} \mathrm{O}: \mathrm{C}, 73.05 \% ; \mathrm{H}, 5.20 \% ; \mathrm{N}$, 2.58\%; Found: C, 73.14\%; H, 5.05\%; N, 2.58\%.

\section{RESULTS AND DISCUSSION}

\section{Phthaloylation Behavior of Chitosan in DMF}

To establish reliable procedures for well-defined phthaloylated chitosan as a key intermediate for controlled chemical modifications, it is necessary to elucidate the phthaloylation behavior in detail. The reaction mixture of fully deacetylated chitosan with three equivalents of phthalic anhydride in DMF at $120^{\circ} \mathrm{C}$ became a homogeneous solution as the substitution proceeded. In $5 \mathrm{~h}$ reaction, the ds was 1.54 as determined by elemental analysis, indicating that hydroxy groups were partially phthaloylated in addition to the amino groups to give $N, O$-phthaloylated chitosan (1) (Scheme 1). The presence of $O$-phthaloyl groups was also confirmed by conductometric titration for the free carboxy groups as shown in Figure 1, and the ds was calculated to be 1.55 , which is in good accordance with the ds by elemental analysis. The ${ }^{1} \mathrm{H}$ NMR spectrum shows peaks at 7.3-7.5 ppm due to $O$-phthaloyl and at 7.5-7.9 ppm due to $N$-phthaloyl (Figure 2). The ds value, however, decreased with an increase in the reaction time as evidenced in Figure 3. The value dropped to 1.18 in $24 \mathrm{~h}$ reaction, and this was also supported by the lowered peaks at 7.3$7.5 \mathrm{ppm}$ in ${ }^{1} \mathrm{H}$ NMR. 


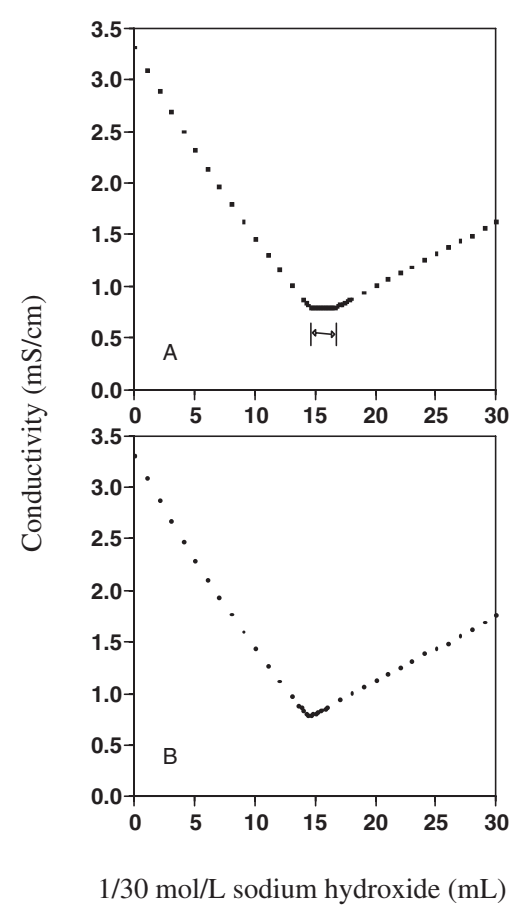

Figure 1. Conductometric titrations for $\mathrm{N}, \mathrm{O}$-phthaloylated chitosan 1 with a ds 1.54 , the arrow corresponding to the amount of free carboxy groups (A), and for $N$-phthaloyl-chitosan $\mathbf{2}$ with a ds 1.0 (B).

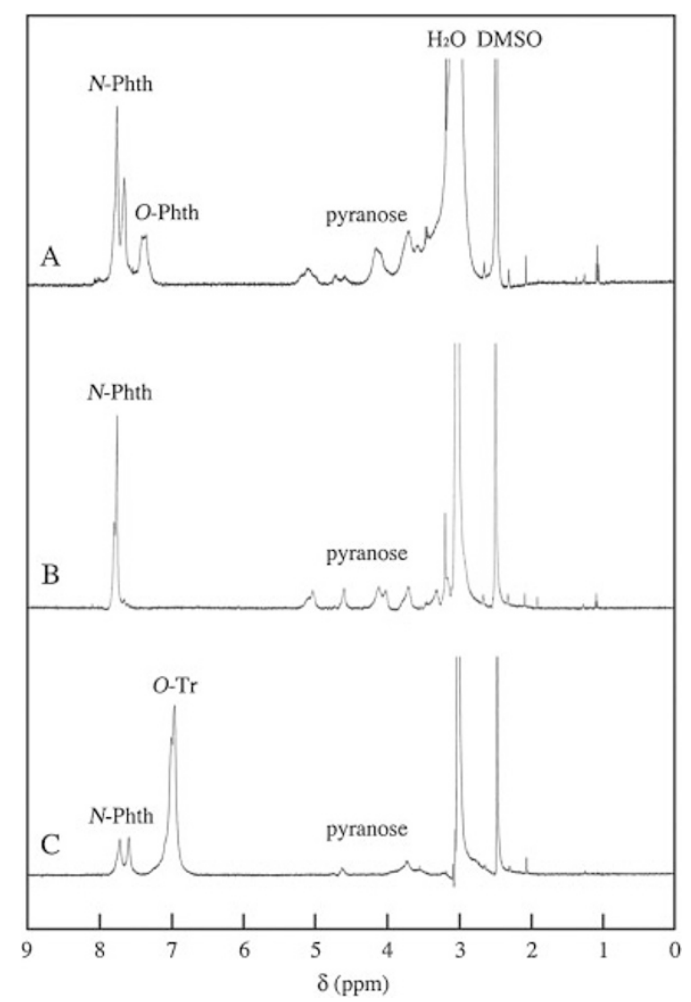

Figure 2. ${ }^{1} \mathrm{H}$ NMR spectra of $N, O$-phthaloylated chitosan $\mathbf{1}$ with a ds 1.54 (A), $N$-phthaloyl-chitosan 2 with a ds 1.0 (B), and 2- $\mathrm{N}$-phthaloyl-6-O-tritylchitosan 3 with a total ds 2.0 (C) in DMSO- $d_{6}$.

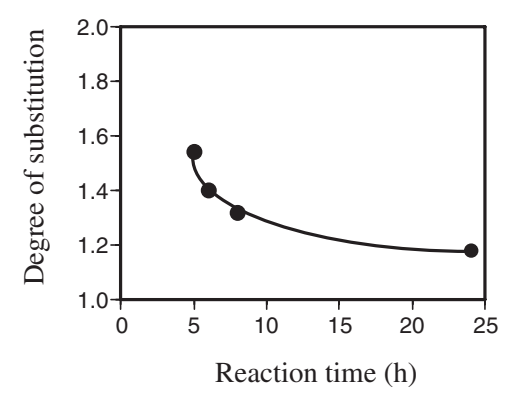

Figure 3. Influence of reaction time on the degree of substitution in the phthaloylation of chitosan in DMF at $120^{\circ} \mathrm{C}$.

Conversion of N,O-Phthaloylated Chitosan 1 to N-Phthaloyl-chitosan 2: a) Tritylation Followed by Detritylation

$O$-Phthaloyl groups of $\mathbf{1}$ could be removed by transesterification with methoxide/methanol to give $\mathrm{N}$ phthaloyl-chitosan (2) (Scheme 2), and the structure was confirmed by ${ }^{1} \mathrm{H}$ NMR, IR, and elemental analysis as reported previously. ${ }^{11}$ However, it was necessary to conduct the reaction for a long time, around $4 \mathrm{~d}$, or to repeat the reaction two or three times for complete removal owing to the reaction under heterogeneous suspension conditions. Moreover, the $\mathrm{N}$-phthaloyl group was not stable under alkaline conditions and tended to decompose to some extent especially in the presence of a small amount of contaminated water. The transesterification thus sometimes lacks reproducibility, and alternative procedures were explored as described below.

To avoid alkaline conditions that could be harmful to the $N$-phthaloyl group, selectively and fully $N$ phthaloylated 2 was synthesized by two-step reactions: tritylation and subsequent detritylation. Phthaloylated chitosan 1 with a ds 1.54 obtained above was converted to the corresponding 6- $O$-tritylated derivative $(3)$ by treating with trityl chloride in pyridine. Though the reaction was not complete at $90^{\circ} \mathrm{C}$ for $24 \mathrm{~h}$ (ds 0.80 ), a fully tritylated product was obtained at $100{ }^{\circ} \mathrm{C}$. The degree of tritylation was 1.0 (elemental analysis and ${ }^{1} \mathrm{H}$ NMR spectroscopy), which indicates that even the 6-O-phthaloyl groups were thoroughly replaced with trityl groups. Subsequent detritylation of $\mathbf{3}$ took place easily in dichloroacetic acid to afford $\mathbf{2}$ (Scheme 2). The structures of $\mathbf{3}$ and $\mathbf{2}$ were confirmed by IR and NMR spectroscopies (Figure 2) and elemental analysis. The peaks due to trityl groups at 6.8-7.2 ppm disappeared in the NMR spectrum of 2 (Figure 2), which was identical with that of the product obtained by transesterification.

Conversion of N,O-Phthaloylated Chitosan 1 to $\mathrm{N}$ Phthaloyl-chitosan 2: b) Hydrolysis or Alcoholysis

The decrease in the ds value during the prolonged 

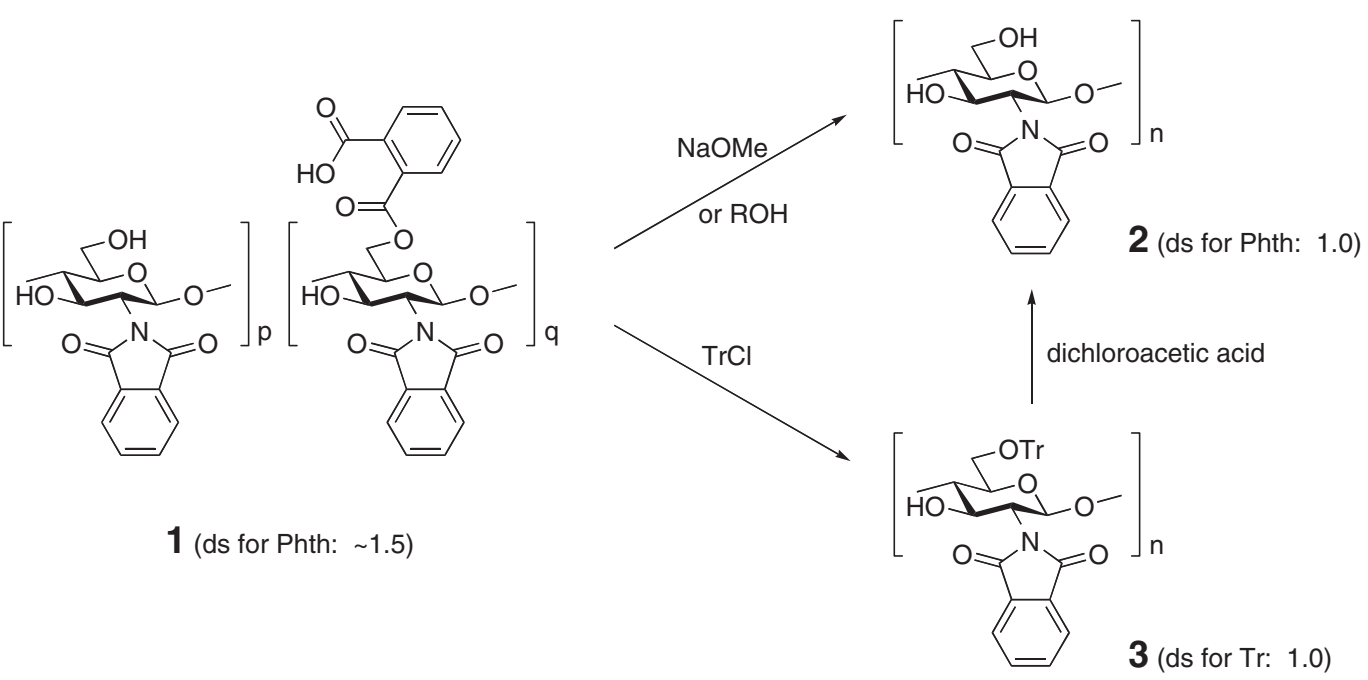

Scheme 2.

reaction in Figure 3 implies that, though $O$-phthaloylation occurs in the initial stage under these conditions, the ester linkage would be eventually cleaved by the water formed in the $N$-phthaloylation process. Hydrolytic or alcoholytic removal of the $O$-phthaloyl group was thus expected to be possible with a hydroxy-bearing cosolvent in DMF.

$\mathrm{N}, \mathrm{O}$-Phthaloylated chitosan 1 was soluble in DMF containing $1-5 \%$ water, but precipitation was observed in about $1.5 \mathrm{~h}$ on heating at $120^{\circ} \mathrm{C}$. As summarized in Table I, DMF containing 1\% water effectively decreased the ds, which supports the above hypothesis. When DMF containing 5\% water was used, the $O$ phthaloyl group was removed completely in $4 \mathrm{~h}$ as confirmed by elemental analysis and IR and NMR spectroscopies (Scheme 2). The NMR spectrum shows no

Table I. $O$-Dephthaloylation of $N, O$-phthaloylated chitosan 1 by hydrolysis or alcoholysis ${ }^{\mathrm{a}}$

\begin{tabular}{|c|c|c|c|}
\hline solvent $(\mathrm{v} / \mathrm{v})$ & $\begin{array}{l}\text { time } \\
\text { (h) }\end{array}$ & $\begin{array}{l}\text { yield } \\
(\%)^{\text {b }}\end{array}$ & $d s^{c}$ \\
\hline DMF/water $(99 / 1)$ & 1 & - & 1.26 \\
\hline DMF/water $(99 / 1)$ & 5 & 37.0 & 1.12 \\
\hline $\mathrm{DMF} /$ water $(97 / 3)$ & 5 & 42.4 & 1.02 \\
\hline $\mathrm{DMF} /$ water $(95 / 5)$ & 1 & 80.2 & 1.19 \\
\hline $\mathrm{DMF} /$ water $(95 / 5)$ & 2 & 86.5 & 1.12 \\
\hline DMF/water $(95 / 5)$ & 3 & 87.0 & 1.05 \\
\hline DMF/water $(95 / 5)$ & 4 & 87.5 & 0.99 \\
\hline DMF/water $(95 / 5)$ & 5 & 76.5 & 1.00 \\
\hline DMF/water $(90 / 10)$ & 5 & 70.3 & 1.01 \\
\hline DMF/ethanol $(95 / 5)$ & 5 & 68.8 & 1.00 \\
\hline DMF/ethylene glycol $(95 / 5)$ & 5 & 83.2 & 0.99 \\
\hline DMF/Methyl Cellosolve $(95 / 5)$ & 5 & 82.0 & 1.02 \\
\hline
\end{tabular}

${ }^{\mathrm{a}}$ The reaction was carried out with $0.100 \mathrm{~g}$ of $\mathbf{1}$ (ds 1.54) in $2 \mathrm{~mL}$ of solvent at $120^{\circ} \mathrm{C}$. ${ }^{b}$ Determined on the basis of the ds value. ${ }^{c}$ Degree of substitution calculated from the $\mathrm{C} / \mathrm{N}$ value of elemental analysis. peaks at 7.3-7.5 ppm ascribable to $O$-phthaloyl groups and was identical with those of the products by transesterification or tritylation-detritylation process.

Other solvent systems containing a 5\% cosolvent such as ethanol, ethylene glycol, and Methyl Cellosolve dissolved 1, and the product precipitated out similarly. These solvents also proved effective to selectively cleave the ester linkage as included in Table I. The yield of 2 was generally high, $70-86 \%$, in spite of the small-scale reactions.

The present procedure for removing $O$-phthaloyl groups is considered superior to the transesterification and tritylation-detritylation methods in that it does not use sodium methoxide or dichloroacetic acid that could possibly facilitate hydrolysis of the $N$-phthaloyl group or degradation of the main chain.

\section{Direct $N$-Phthaloylation in DMF/Cosolvent}

The results obtained above suggest that the presence of hydroxy-bearing cosolvents is a key to achieve selective $N$-phthaloylation without $O$-phthaloylation. As summarized in Table II, the reaction was still not regioselective in $8 \mathrm{~h}$ in DMF with $1 \%$ water, but became selective in $24 \mathrm{~h}$ (Scheme 3). DMF containing 5\% water was much more suitable for direct $N$-phthaloylation, and selective and quantitative phthaloylation was attained in 6-24h. In addition to IR, NMR, and elemental analysis, conductometric titration also supported the absence of either free amino groups or carboxy groups (Figure 1), indicating the facile formation of $\mathbf{2}$.

In the presence of water, 1 or $5 \%$, the reaction mixture became a homogeneous solution in $1 \mathrm{~h}$ and then a jelly-like substance unlike the reaction in DMF that proceeded in homogeneous solution. This implies that regioselectively $N$-substituted derivative $\mathbf{2}$ is less soluble than $N, O$-substituted derivative $\mathbf{1}$. 
Table II. Phthaloylation of chitosan in DMF/cosolvents

\begin{tabular}{lrrr}
\hline \multicolumn{1}{c}{ solvent (v/v) } & $\begin{array}{c}\text { time } \\
(\mathrm{h})\end{array}$ & $\begin{array}{c}\text { yield } \\
(\%)^{\mathrm{b}}\end{array}$ & $\mathrm{ds}^{\mathrm{c}}$ \\
\hline DMF/water (99/1) & 5 & 78.5 & 1.12 \\
DMF/water (99/1) & 8 & 84.9 & 1.11 \\
DMF/water (99/1) & 24 & 87.7 & 1.03 \\
DMF/water (95/5) & 5 & 88.0 & 0.98 \\
DMF/water (95/5) & 6 & 96.2 & 1.00 \\
DMF/water (95/5) & 8 & 81.1 & 1.00 \\
DMF/water (95/5) & 14 & 81.7 & 0.98 \\
DMF/water (95/5) & 24 & 79.4 & 1.02 \\
DMF/ethanol (95/5) & 8 & 87.5 & 0.66 \\
DMF/ethylene glycol (95/5) & 8 & 85.9 & 0.50 \\
DMF/Methyl Cellosolve (95/5) & 8 & 86.6 & 0.80 \\
\hline
\end{tabular}

${ }^{\text {a }}$ The reaction was carried out with $0.300 \mathrm{~g}$ of chitosan with 3 equiv of phthalic anhydride in $6 \mathrm{~mL}$ of solvent at $120^{\circ} \mathrm{C}$. ${ }^{b}$ Determined on the basis of the ds value. ${ }^{\mathrm{c} D e g r e e}$ of substitution calculated from the $\mathrm{C} / \mathrm{N}$ value of elemental analysis.
Table III. Solubility ${ }^{\mathrm{a}}$

\begin{tabular}{|c|c|c|c|c|}
\hline & chitin & chitosan & $2^{\mathrm{b}}$ & $\mathbf{1}^{\mathrm{c}}$ \\
\hline DMF & - & - & \pm & + \\
\hline DMSO & - & - & $+^{\mathrm{d}}$ & + \\
\hline pyridine & - & - & \pm & + \\
\hline$m$-cresol & - & - & + & + \\
\hline DCA & - & - & + & + \\
\hline DMAc/LiCl & + & - & + & + \\
\hline $\mathrm{MeOH} / \mathrm{CaCl}_{2}$ & + & - & + & + \\
\hline $5 \%$ AcOHaq & - & + & - & - \\
\hline
\end{tabular}

${ }^{a} \mathrm{DMF}, N, N$-dimethylformamide; DMSO, dimethyl sulfoxide; DCA, dichloroacetic acid; DMAc/LiCl, N,N-dimethylacetamide containing $8 \% \mathrm{LiCl} ; \mathrm{MeOH} / \mathrm{CaCl}_{2}$, methanol saturated with $\mathrm{CaCl}_{2}$ dihydrate; + , soluble; \pm , partially soluble or swelled; - insoluble. ${ }^{\mathrm{b}} \mathrm{N}$-Phthaloyl-chitosan (ds 1.0). ${ }^{\mathrm{c}} \mathrm{N}, \mathrm{O}-$ Phthaloylated chitosan (ds 1.54). ${ }^{\mathrm{d}} \mathrm{A}$ small amount of highly swollen gel often formed when 2 was prepared in one step in $\mathrm{DMF} /$ water $(95 / 5)$.

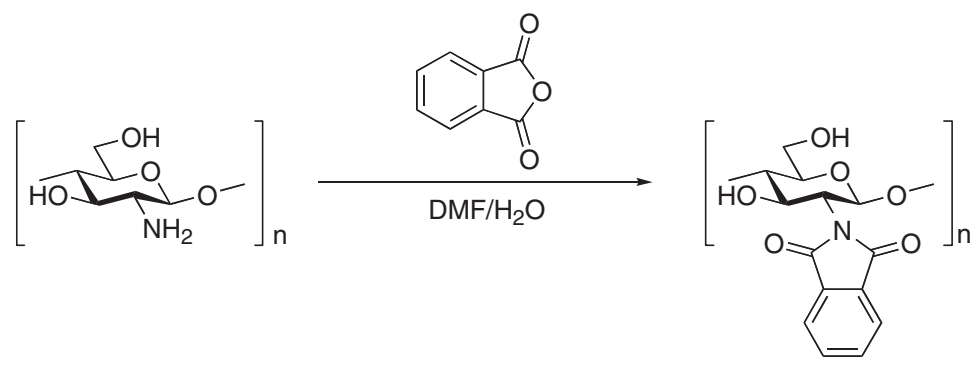

2

Scheme 3.

The mixed solvent systems of DMF containing alcohols such as ethanol, ethylene glycol, and Methyl Cellosolve were, however, not proper judging from the ds values, probably because the mixtures in these solvents failed to give homogeneous solutions during the process. Water was thus superior to these alcohols as a cosolvent, and phthaloylation in $\mathrm{DMF} /$ water $(95 / 5)$ at $120^{\circ} \mathrm{C}$ for $5-8 \mathrm{~h}$ proved to be suitable for regioselective and quantitative protection to give $\mathbf{2}$ in a simple one step reaction.

\section{Solubility}

Though chitin and chitosan are not soluble in ordinary solvents, $\mathrm{N}$-substituted derivative $\mathbf{2}$ was soluble in some solvents such as dichloroacetic acid, $m$-cresol, $N, N$-dimethylacetamide/ $\mathrm{LiCl}$, and $\mathrm{MeOH} /$ $\mathrm{CaCl}_{2} \cdot 2 \mathrm{H}_{2} \mathrm{O}$ as listed in Table III. It was also soluble in DMSO if it was derived from 1 by $O$-dephthaloylation (transesterification, phthaloylation-dephthaloylation, hydrolysis, or alcoholysis). However, 2 prepared in one step exhibited somewhat lower solubility in general: it was almost soluble in DMSO, but a trace amount of highly swollen transparent gel often remained. $\mathrm{N}, \mathrm{O}$-Substituted derivative $\mathbf{1}$ showed much higher solubility because of the bulky structure and amorphous nature in contrast to the crystalline structure of $\mathbf{2}$ as reported in our previous communication. ${ }^{14}$

\section{Deprotection}

$N$-Protected chitosan $\mathbf{2}$ is a convenient precursor for chemical modifications, since after modification reactions, the protecting $\mathrm{N}$-phthaloyl group can be removed with hydrazine to regenerate the free amino group. In the hydrazinolysis of 2 at $80^{\circ} \mathrm{C}$, the reaction proceeded in a heterogeneous suspension state, and after $7 \mathrm{~h}$ there still remained some phthaloyl groups as evidenced in the IR spectrum. Complete deprotection was attained in $16 \mathrm{~h}$ to regenerate chitosan. However, $\mathrm{N}, \mathrm{O}$-phthaloylated derivative 1 underwent hydrazinolysis easier owing to the solubility in hydrazine; the mixture was a homogeneous solution initially, but precipitation occurred in $3 \mathrm{~h}$ at $80^{\circ} \mathrm{C}$. The reaction was complete in $7 \mathrm{~h}$, removing both the $N$ - and $O$ phthaloyl groups. 
Table IV. Tritylation of $N$-phthaloyl-chitosan 2 and $N, O$-phthaloylated chitosan $\mathbf{1}^{\text {a }}$

\begin{tabular}{cccccc}
\hline $\begin{array}{c}\text { phthaloylated } \\
\text { chitosan }\end{array}$ & $\begin{array}{c}\text { DMAP/ } \\
\text { pyranose }^{\mathrm{b}}\end{array}$ & $\begin{array}{c}\text { temp } \\
\left({ }^{\circ} \mathrm{C}\right)\end{array}$ & $\begin{array}{c}\text { time } \\
(\mathrm{h})\end{array}$ & $\begin{array}{c}\text { yield } \\
(\%)^{\mathrm{c}}\end{array}$ & $\mathrm{ds}^{\mathrm{d}}$ \\
\hline $\mathbf{2}$ & - & 70 & 24 & 82.0 & 0.82 \\
$\mathbf{2}$ & - & 80 & 24 & 82.8 & 0.86 \\
$\mathbf{2}$ & 5 & 80 & 24 & 82.9 & 0.85 \\
$\mathbf{2}$ & - & 80 & 48 & 77.0 & 1.00 \\
$\mathbf{2}$ & - & 90 & 24 & 86.5 & 1.00 \\
$\mathbf{1}$ & - & 90 & 24 & 85.7 & 0.80 \\
$\mathbf{1}$ & - & 100 & 24 & 87.8 & 1.00 \\
\hline
\end{tabular}

${ }^{\text {a }}$ The reaction was carried out with $0.200 \mathrm{~g}$ of $\mathbf{2}$ (ds 1.0) or $\mathbf{1}$ (ds 1.54 ) with 10 equiv of trityl chloride in $5 \mathrm{~mL}$ of pyridine. ${ }^{\mathrm{b}}$ Mole ratio (DMAP, dimethylaminopyridine). ${ }^{\mathrm{c}}$ Determined on the basis of the ds value. ${ }^{\mathrm{d}}$ Degree of substitution calculated from the $\mathrm{C} / \mathrm{N}$ value of elemental analysis.

\section{Reactivity}

The possibility of $\mathrm{N}$-protected derivative $\mathbf{2}$ as a reaction precursor was evaluated in tritylation, a typical protection for the primary hydroxy group, since the resulting tritylated product $\mathbf{3}$ is an important precursor to prepare tritylated chitosan useful in chemical modifications of the amino group. The reaction with trityl chloride in pyridine at $70^{\circ} \mathrm{C}$ was insufficient, and dimethylaminopyridine was not effective as the catalyst as shown in Table IV. Full tritylation was, however, achieved at $80^{\circ} \mathrm{C}$. The structure was confirmed by IR, NMR, and elemental analysis. The ${ }^{1} \mathrm{H}$ NMR spectrum was identical with that of $\mathbf{3}$ prepared by tritylation of 1 in Figure 2. When $N, O$-phthaloylated derivative 1 was subjected to tritylation, a higher temperature such as $100^{\circ} \mathrm{C}$ was necessary because of the replacement of the $O$-phthaloyl groups (Table IV). These results indicate that regioselectively $\mathrm{N}$-protected chitosan 2 is much more versatile to synthesize a variety of $O$-substituted derivatives, although 1 could also be used in tritylation.

\section{CONCLUSIONS}

Though phthaloylation of chitosan in DMF gave $\mathrm{N}, \mathrm{O}$-phthaloylated product 1 with a ds up to 1.5 , it could be converted to $\mathrm{N}$-phthaloylated derivative $\mathbf{2}$ with a ds 1.0 on removing the $O$-phthaloyl groups by appropriate methods. However, phthaloylation in the presence of some water successfully discriminated the functional groups, giving rise to regioselectively and fully $\mathrm{N}$-phthaloylated chitosan $\mathbf{2}$ in a one-step reaction. This is a facile and convenient method to prepare structurally well-defined 2 . The product proved to be superb as an intermediate to introduce substituents at the C-6 position and is expected to expand the scope of chemical modifications of multi- functional and poorly soluble chitosan to construct desirable molecular architectures based on polysaccharides.

Acknowledgment. This work was partially supported by "High-Tech Research Center" Project for Private Universities: matching fund subsidy from MEXT, 2004-2008.

\section{REFERENCES}

1. a) T. D. Rathke and S. M. Hudson, J. Macromol. Sci., Rev. Macromol. Chem. Phys., C34, 375 (1994).

b) “Applications of Chitin and Chitosan," M. F. A. Goosen, Ed., Technomic, Lancaster, PA, 1997.

c) K. Kurita, Polym. Degrad. Stab., 59, 117 (1998).

d) M. N. V. Ravi Kumar, React. Funct. Polym., 46, 1 (2000). e) T. Uragami and S. Tokura, in "Material Science of Chitin and Chitosan," Kodansha, Tokyo, 2006.

2. a) G. A. F. Roberts, "Chitin Chemistry," Macmillan, London, 1992.

b) K. Kurita, in "Polymeric Materials Encyclopedia," J. C. Salamone, Ed., CRC, Boca Raton, 1996, Vol. 2, pp 12051208.

c) K. Kurita, in "Desk References of Functional Polymers: Syntheses and Applications," R. Arshady, Ed., American Chemical Society, Washington, D. C., 1997, pp 239-259.

d) S. M. Hudson and C. Smith, in "Biopolymers from Renewable Resources,” D. L. Kaplan, Ed., Springer, Berlin, 1998, chap. 4.

e) K. Kurita, Prog. Polym. Sci, 26, 1921 (2001).

f) D. W. Jenkins and S. M. Hudson, Chem. Rev., 101, 3245 (2001).

g) K. Kurita, in "Material Science of Chitin and Chitosan," T. Uragami and S. Tokura, Ed., Kodansha, Tokyo, 2006, pp 51-79.

h) K. Kurita, Mar. Biotechnol., 8, 203 (2006).

3. K. Kurita, H. Ichikawa, S. Ishizeki, H. Fujisaki, and Y. Iwakura, Makromol. Chem., 183, 1161 (1982).

4. S. Nishimura, O. Kohgo, K. Kurita, and H. Kuzuhara, Macromolecules, 24, 4745 (1991).

5. a) K. Kurita, H. Akao, M. Kobayashi, T. Mori, and Y. Nishiyama, Polym. Bull., 39, 543 (1997).

b) K. Kurita, K. Shimada, Y. Nishiyama, M. Shimojoh, S. Nishimura, Macromolecules, 31, 4764 (1998).

c) K. Kurita, T. Kojima, Y. Nishiyama, and M. Shimojoh, Macromolecules, 33, 4711 (2000).

d) K. Kurita, H. Akao, J. Yang, and M. Shimojoh, Biomacromolecules, 4, 1264 (2003).

e) J. Yang, H. Akao, M. Shimojoh, and K. Kurita, Chitin Chitosan Res., 10, 51 (2004).

6. a) S. Nishimura, Y. Miura, L. Ren, M. Sato, A. Yamagishi, N. Nishi, S. Tokura, K. Kurita, and S. Ishii, Chem. Lett., 1623 (1993).

b) S. Nishimura, H. Kai, K. Shinada, T. Yoshida, S. Tokura, K. Kurita, H. Nakashima, N. Yamamoto, and T. Uryu, Carbohydr. Res., 306, 427 (1998).

7. a) T. Ouchi, H. Nishizawa, and Y. Ohya, Polymer, 39, 5157 
(1998).

b) Y. Ohya, R. Cai, H. Nishizawa, K. Hara, and T. Ouchi, Pharm. Sci., 10, 77 (2000).

8. a) Y. Nishiyama, T. Yoshikawa, K. Kurita, K. Hojo, H. Kamada, Y. Tsutsumi, T. Mayumi, and K. Kawasaki, Chem. Pharm. Bull., 47, 451 (1999).

b) Y. Nishiyama, T. Yoshikawa, N. Ohara, K. Kurita, K. Hojo, H. Kamada, Y. Tsutsumi, T. Mayumi, and K. Kawasaki, J. Chem. Soc., Perkin Trans. 1, 1161 (2000).

c) K. Kurita, M. Hayakawa, Y. Nishiyama, and M. Harata, Carbohydr. Polym., 47, 7 (2002).

9. a) J. Holappa, T. Nevalainen, J. Svolainen, P. Soininen, M. Elomaa, R. Safin, S. Suvanto, T. Pakkanen, M. Másson, T. Loftsson, and T. Järvinen, Macromolecules, 37, 2784 (2004).

b) J. Holappa, T. Nevalainen, P. Soininen, M. Elomaa, R. Safin, M. Másson, and T. Järvinen, Biomacromolecules, 6, 858 (2005). c) J. Holappa, T. Nevalainen, R. Safin, P. Soininen, T. Asplund, T. Luttikhedde, M. Másson, and T. Järvinen, Macromol. Biosci., 6, 139 (2006).

10. D. K. Rout, S. K. Pulapura, and R. A. Gross, Macromolecules, 26, 5999 (1993).

11. K. Kurita, M. Uno, Y. Saito, and Y. Nishiyama, Chitin Chitosan Res., 6, 43 (2000).

12. a) D. K. Rout, S. K. Pulapura, and R. A. Gross, Macromolecules, 27, 6007 (1993).

b) D. K. Rout, S. P. Barman, S. K. Pulapura, and R. A. Gross, Macromolecules, 27, 2945 (1994).

13. a) R. Yoksan, M. Akashi, K. I. Hiwatari, and S. Chirachanchai, Biopolymers, 69, 386 (2003).

b) R. Yoksan, M. Matsusaki, M. Akashi, and S. Chirachanchai, Colloid Polym. Sci., 282, 337 (2004).

14. K. Kurita, H. Ikeda, Y. Yoshida, M. Shimojoh, and M. Harata, Biomacromolecules, 3, 1 (2002). 